\title{
The using of gene-oriented SCOT markers in genotyping of the Apple genus (Malus Mill.)
}

\author{
Ilya Stepanov*, Ilnur Balapanov, Elena Lobodina, and Ivan Suprun ${ }^{1}$ \\ Federal State Budget Scientific Institution «North Caucasian Federal Scientific Center of \\ Horticulture, Viticulture, Wine-making», 39 str. 40 Let Pobedy, Krasnodar, 350901, Russia
}

\begin{abstract}
This paper discusses the aspects of optimization of the SCoT genotyping method for representatives of the genus Apple (Malus Mill.), including the orchard apple (Malus domestica). Special attention is paid to the methods of total DNA isolation from apple plant tissue, which is due to the sensitivity of multilocus marker systems to the quality of the nucleic acid preparation. On a sample of total DNA isolated from the leaves of the Golden Delicious cultivar, 18 SCoT markers were tested, from which 4 Malus Mill cultivars and species most promising for genotyping were selected.
\end{abstract}

\section{Introduction}

Maintaining high planting material varietal purity is one of the leading factors in the effective horticultural system management. To achieve the maximum effect, it is recommended to control varietal purity not only at the stage of production of planting material in specialized nurseries, but also in industrial plantings, both with the participation of the horticultural enterprises themselves, and with the involvement of sectoral control bodies and scientific institutions with the proper competence. The control of varietal purity is most importantly updated when purchasing foreign planting material. In this regard, express methods are needed to assess the varietal affiliation of the planting material at the stage of one-two-year-old seedlings. Such methods will ensure the proper quality of the planting material in terms of varietal purity. DNA-markers have proven to be a reliable approach to solving the problem of planting material identification. A new type of molecular marker known as Start Codon Targeted (SCoT) targeting a short ATG start codon in plant genes was developed by a team leded Collard and Mackill. This marker system has several advantages over more common marker types such as RAPD, ISSR and AFLP. These advantages include the stability of genotyping results, the presence of a larger number of amplified DNA fragments, and the reliability of the information obtained, which is due to the linked inheritance of these markers with functional plant genes.

Thus, SCoT markers are an effective tool for population studies, assessment of genetic diversity and structure, identification of genotypes by obtaining unique fingerprints. [12]. The advantageous pluses of SCoT genotyping include ease of use and low cost of analysis [3]. SCoT markers have been successfully used to assess genetic diversity and identify

\footnotetext{
*Corresponding author: ivstepanof@gmail.com
} 
grapes [4], jatropha [5], orchardgrass [6], andrographis [7], yew [8] and rose [9], palm [10], plantain [11 ], pistachios [12], durum wheat [13], common wheat [14] and walnuts.

The aim of this work is to test various approaches for DNA isolation on young leaves of an apple tree and to test SCoT markers for further use of optimal methods in genotyping representatives of the genus Malus Mill.

\section{Materials and methods}

The work on the optimal method selection for DNA extraction was carried out on young leaves of an orchard apple (variety Golden Delicious) and crab (Hiden rose). Were involved three commercial protocols of various price categories developed for the isolation of DNA plants: MagnoPrime PHYTO (AmpliPrime), Proba NK (Agrodiagnostics), Dneasy Plant mini kit (QIAGEN). Also, a modified CTAB method was used, which was previously used in the research of fruit crops [15].

The PCR reaction took place under the following conditions according to the standard parameters of SCoT genotyping: Concentration of PCR reagents mixture: Buffer 1X, dNTP - $0.24 \mathrm{mM}$, Taq 1U, SCoT primers - $0.32 \mu \mathrm{M}$, total DNA - 40ng.

Temperature set for PCR: 3 minutes of initial denaturation $\left(94{ }^{\circ} \mathrm{C}\right) ; 42$ cycles: 20 seconds denaturation $\left(94^{\circ} \mathrm{C}\right), 30$ seconds primer annealing $\left(50{ }^{\circ} \mathrm{C}\right), 2$ minutes elongation $\left(72{ }^{\circ} \mathrm{C}\right)$; final elongation 10 minutes $\left(72^{\circ} \mathrm{C}\right)$.

Electrophoresis was carried out at a voltage of $5.6 \mathrm{~V} / \mathrm{cm}$ for an hour, the agarose gel was stained with ethidium bromide. The analysis and calculation of spectrophotometric parameters were carried out on a nanophotometer n80-touch device.

\section{Results and discussion}

Testing of DNA extraction methods. For reliable genotyping of apple varieties using SCoT markers, a high-quality DNA preparation is required. In this work, 4 methods of DNA isolation on young leaves of the spring-early summer season were evaluated. Were used 3 methods, which are commercial protocols for the isolation of nucleic acids. These commercial protocols varied both in the cost of isolating one sample and in the method of DNA purification. MagnoPrime PHYTO method based on the use of magnetic particles. Proba NK is a method consisting in washing the DNA precipitate with alcohol-containing solutions. Dneasy Plant Mini Kit - DNA filtration through columns.

The work also included a modified CTAB-method, common in laboratory practice. The quality of DNA preparation was assessed according to the spectrophotometer data (concentration of nucleic acids, the ratio of protein to nucleic acids), denaturing electrophoresis in agarose gel (DNA structure), and PCR setup (amount of PCR product produced). The quality indicators of the isolated DNA preparations are presented in Tab. 1.

The parameters of DNA purity established using a spectrophotometer depended on the method and, to a lesser extent, on the type of sample (apple variety or crab apple). The highest concentrations of nucleic acids were found in samples isolated by the CTAB method (on average $7839.9 \mathrm{ng} / \mu \mathrm{L}$ per sample), the lowest concentration of nucleic acids was found in samples isolated by the Proba NK method (on average, $6.400 \mathrm{ng} / \mu \mathrm{L}$ per sample). A twofold predominance of nucleic acids in relation to protein was revealed in samples obtained by CTAB and Dneasy Plant Mini Kit methods. The best indicators of the ratio of nucleic acids to carbohydrates were also characteristic of the samples obtained by these two methods. 
Table 1. Quality indicators of the DNA samples

\begin{tabular}{|l|l|l|l|}
\hline Наименование образца ДНК & $\begin{array}{l}\text { NA Concentration } \\
\text { ng/ } \mu \mathrm{l}\end{array}$ & $260 / 280$ o. u. & 260/230 o. u. \\
\hline Apple, MagnoPrime PHYTO & 43,350 & 2,074 & 0,804 \\
\hline Crab apple, MagnoPrime PHYTO & 74,000 & 2,102 & 1,448 \\
\hline Apple, Proba NK & 6,4500 & 1,985 & 0,035 \\
\hline Crab apple, Proba NK & 6,3500 & 1,841 & 0,035 \\
\hline Apple, Dneasy Plant Mini Kit & 53,500 & 1,942 & 3,075 \\
\hline $\begin{array}{l}\text { Crab apple, Dneasy Plant Mini } \\
\text { Kit }\end{array}$ & 51,950 & 1,960 & 3,384 \\
\hline Apple, CTAB - method & 6710,0 & 2,161 & 2,420 \\
\hline Crab apple, CTAB - method & 8969,8 & 2,190 & 2,430 \\
\hline
\end{tabular}

Agarose gel electrophoresis of DNA samples provided general information about the integrity of the isolated DNA (Fig. 1). The DNA obtained by the CTAB method was strongly degraded during isolation, as evidenced by low-molecular-weight DNA fragments found in large quantities on the electrophoretogram. However, the significant degradation of DNA preparations is partly offset by the high concentration of nucleic acids. The most complete total DNA was obtained by the Dneasy Plant Mini Kit method.

The amount of product amplified during the polymerase chain reaction depends on various factors, such as the concentration of nucleic acids, the degree of total DNA degradation, and the presence of concomitant substances in the sample acting as PCR inhibitors (Fig. 1). Based on the results of PCR for 4 isolation methods and two genotypes of crab and apple, we can conclude that the methods of MagnoPrime PHYTO and Dneasy Plant Mini Kit allows to get good amplification in both orchard apple and crab. Crab samples obtained by NK Probe and CTAB-method did not have amplification.

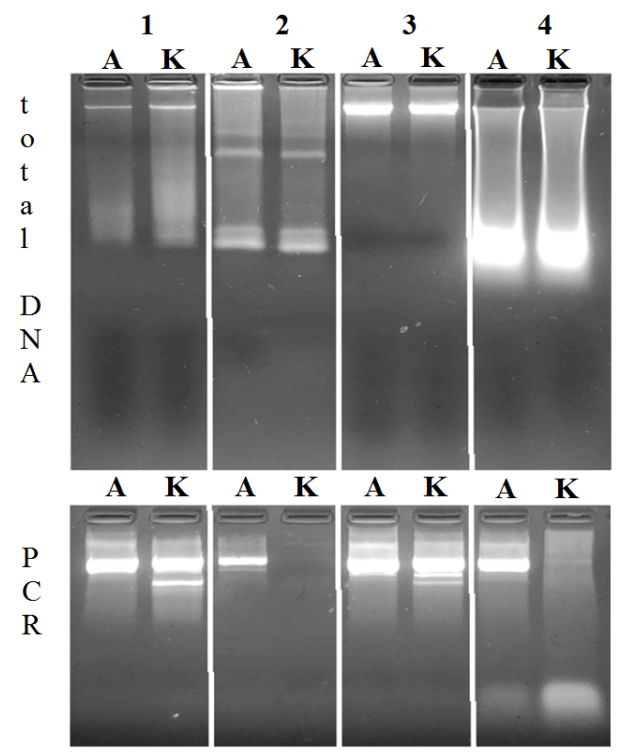

Fig. 1. DNA preparations quality isolated using 4 methods 1 - MagnoPrime PHYTO; 2 - NA sample; 3 - Dneasy Plant Mini Kit; 4 - CTAB-method, A genotype of orchard apple, $\mathrm{K}$ - genotype of crab. 
In the course of comparison of the methods, it was found that of the commercial kits used, the best results are shown by the method using columns, the worst method by alcohol washing of the precipitate. The laboratory CTAB method made it possible to obtain the largest amount of nucleic acid in the samples, but most of it is severely damaged, which affects the PCR results. In addition to samples of orchard apple, samples of wild apple were taken, containing a significant amount of phenolic compounds and anthocyanins. Based on the results of PCR, it can be argued that the methods using columns and magnetic particles make it possible to purify preparations from concomitant substances that interfere with the PCR. PCR in two other methods was inhibited.

Testing SCoT markers on apple genotypes. We analyzed the amplification products of 18 SCoT markers tested on a DNA sample isolated from the Golden Delicious variety (Fig. 2).

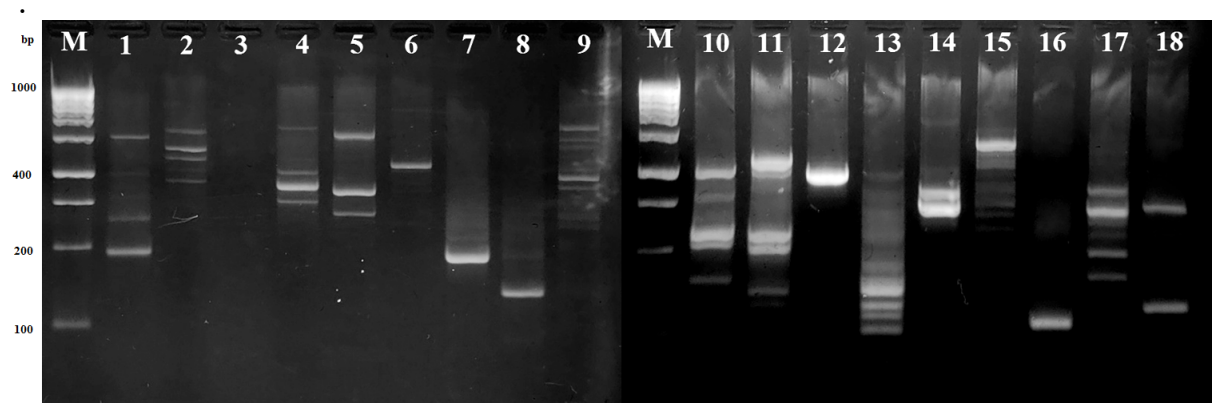

Fig. 2. Electropherogram of PCR products of 18 SCoT markers on the Golden Delicious variety: 1 SCoT1, 2 - SCoT2, 3 - SCoT3, 4 - SCoT4, 5 - SCoT6, 6 - SCoT8, 7 - SCoT11, 8 - SCoT12, 9 SCoT13, 10 - SCoT14, 11 - SCoT15, 12 - SCoT16, 13 - SCoT18, 14 - SCoT19, 15 - SCoT20, 16 SCoT21, 17 - SCoT28, 18 - SCoT29, M - molecular weight marker.

The selection of markers suitable for further use in the genotyping of apple samples was carried out on the basis of two most important indicators, the clarity and the number of DNA fragments (Table 2).

Table 2. Results of testing SCoT markers on apple cultivar Golden Delicious

\begin{tabular}{|l|l|l|l|}
\hline Marker name & Number of fragments & Marker name & Number of fragments \\
\hline SCoT1 & 5 & SCoT14 & 6 \\
\hline SCoT2 & 5 & SCoT15 & 6 \\
\hline SCoT3 & - & SCoT16 & 1 \\
\hline SCoT4 & 4 & SCoT18 & 10 \\
\hline SCoT6 & 3 & SCoT19 & 4 \\
\hline SCoT8 & 1 & SCoT20 & 5 \\
\hline SCoT11 & 1 & SCoT21 & 1 \\
\hline SCoT12 & 1 & SCoT28 & 6 \\
\hline SCoT13 & 7 & SCoT29 & 2 \\
\hline
\end{tabular}

Amplification failed only for one SCoT marker (SCoT3). The largest number of DNA fragments was found in the SCoT18 marker (10), as well as a significant number of amplified bands was found in the SCoT14, SCoT15, and SCoT28 markers (6). The markers SCoT8, SCoT11, SCoT12, SCoT16, SCoT21 are not promising for further use for genotyping; only one DNA fragment was identified in them during the approbation process. Thus, the markers identified at this stage include SCoT 14, SCoT 15, SCoT 18, SCoT 28. 


\section{Conclusion}

The information obtained in this work can be further used in the adaptation of SCoT methods for genotyping the orchard apple and other representatives of the genus Malus Mill. The comparative advantages of the approaches involved in the extraction of DNA samples have been established. The relationship between the quality of the isolated DNA and the efficiency of PCR using SCoT markers was determined. It should be noted that a number of factors serving as inhibitors of the polymerase chain reaction are detected only when DNA amplification is performed. The testing of the SCoT set of markers made it possible to establish a number of primers that are most promising for further use. In general, the article is of a methodological nature and suggests further work on the introduction of SCoT markers into genetic studies of the culture of orchard apple trees and representatives of the genus Malus Mill ..

Acknowledgments. The study was carried out with the financial support of the Kuban Science Foundation within the framework of the scientific project No. NIP-21.1/16

\section{References}

1. P. Poczai, I. Varga, M. Laos, A. Cseh, N. Bell, H.P. Valkonen, J. Hyvonen, Plant Methods 9, 6 (2013) https://doi.org/10.1186/1746-4811-9-6

2. A. Etminan, A.R. Pour-Aboughadareh, R. Mohammadi, A. AhmadiRad, A. Noori, Z. Mahdavian, Z. Moradi, Biotechnol. Biotechnol. Equip., 30(6), 1075-1081 (2016) https://doi.org/10.1080/13102818.2016.1228478

3. X.T. Chai, R. Dong, W.X. Liu, Y.R. Wang, Z.P. Liu, Molecules, 22(4), 567 (2017) https://doi.org/10.3390/molecules22040567

4. D.L. Guo, J.Y. Zhang, C.H. Liu, Mol. Biol. Rep., 39, 5307-5313 (2012) https://doi.org/10.1007/s11033-011-1329-6

5. L.S. Mulpuri, T. Muddanuru, G. Francis, Plant. Sci., 207, 117-127 (2013) https://doi.org/10.1016/j.plantsci.2013.02.013

6. B. Zeng, Y. Zhang, L.K. Huang, X.M. Jiang, D. Luo, G. Yin., Biochem. Syst. Ecol., 54, 96-102 (2014) https://doi.org/10.1016/j.bse.2013.12.028

7. G. Tiwari, R. Singh, N. Singh, D.R. Choudhury, R. Paliwal, A. Kumar, V. Gupta, Ind. Crops Prod., 86, 1-11 (2016) https://doi.org/10.1016/j.indcrop.2016.03.031

8. J. Hao, K. Jiao, C. Yu, H. Guo, Y. Zhu, X. Yang, S. Zhang, L. Zhang, S. Feng, Y. Song, M. Dong, H. Wang, C. Shen., Biochem. Genet., 56, 255-266 (2018) https://doi.org/10.1007/s10528-018-9842-0

9. A. Agarwal, V. Gupta, S. Haq, P. Jatav, S.L. Kothari, S. Kachhwaha, J. King Saud Univ. Sci., 31(4), 780-788 (2018) https://doi.org/10.1016/j.jksus.2018.04.022

10. S. Saboori, Z. Noormohammadi, M. Sheidai, S.S. Marashi, Genet. Resour. Crop. Evol., 67, 73-82 (2019) https://doi.org/10.1007/s10722-019-00854-X

11. M. Rahimi, L. Nazari, M. Kordrostami, P. Safari, Sci. Hortic., 233, 302-309 (2018) https://doi.org/10.1016/j.scienta.2018.01.009

12. A. Baghizadeh, E. Dehghan, Pist. Health J., 1(1), 37-43 (2018) http://doi.org/10.22123/PHJ.2017.54299

13. H. Hamidi, R. Talebi, F. Keshavarzi, Cereal Res. Commun., 42(4), 558-567 (2014) https://doi.org/10.1556/CRC.2014.0010

14. M. Tabasi, M. Sheidai, D. Hassani, F. Koohdar, Genet. Resour. Crop. Evol., 67, 14371447 (2020) https://doi.org/10.1007/s10722-020-00914-7

15. I.I. Suprun, I.V. Stepanov, S.V. Tokmakov, G.V. Eremin, Russ. J. Genet., 55, 172-179 (2019) https://doi.org/10.1134/S1022795419010149 